\title{
The influence of social relationships on men's weight
}

\author{
Kimberley Anne Harcourt, Jane Appleton, Miriam E. Clegg, Louise Hunter
}

\section{INTRODUCTION}

There is a clear link between the development of obesity with poor diet and exercise behaviours ${ }^{1}$. In the UK, excess weight is more prevalent among men than women: $41 \%$ of men and $31 \%$ of women are classed as overweight (BMI $\left.25.0-29.9 \mathrm{~kg} / \mathrm{m}^{2}\right)$; $68 \%$ and $58 \%$ of men and women respectively are overweight or obese (BMI $\geq 25$ $\left.\mathrm{kg} / \mathrm{m}^{2}\right)^{2}$. An increase in BMI is also associated with a greater risk of mortality in men than in women ${ }^{3}$ however men are under-represented in lifestyle interventions for weight loss 4 : In 2016, 7\% of Slimming World members were men ${ }^{5}$. It has been argued that men may perceive larger bodies to be more masculine and more desirable to women ${ }^{6}$. Furthermore, factors contributing to male obesity such as eating large portions and consuming large volumes of alcohol, can be viewed as quintessentially masculine behaviours $6-8$.

To promote weight loss and reduce obesity among men, it is useful to understand which social interactions influence male weight loss behaviours. It is known that men in heterosexual relationships often gain weight after getting married $^{9}$ however the extent of women's influence on men's food intake and weight is unclear. Research studies investigating the influence that women and female partners have on male dietary and weight loss have been mixed; while some suggests they have a positive impact, ${ }^{10}$ other research suggests the impact is mixed or negative ${ }^{11-15}$. Friends, peers and colleagues are also referenced regarding men's diet and physical activity behaviours and behavioural intentions ${ }^{16}$. The qualitative literature in the UK which 
explores how social relationships influence men's weight and weight-related behaviours is, however, limited, therefore this research study sought to address this literature gap. The primary research question was to explore men's perceptions and attitudes of dietary and physical activity behaviours in relation to weight and weight management.

\section{METHOD}

\section{Study Design}

A qualitative design was used to explore the subjective experiences and perceptions of men surrounding their dietary, physical activity and weight loss behaviours. The Theory of Planned Behaviour (TPB $)^{17}$, which has been found to be a valuable tool to explain and understand behaviours, was used to interpret the findings.

\section{Procedure}

Participants were recruited over a five-month period by author 1 using convenience sampling. Recruitment posters were placed in shop windows in a County in the South West of England and on social media platforms. Posters detailed the nature of the study and invited interested individuals to contact the lead author for an information sheet. The study was conducted among men in the target County with a $\mathrm{BMI} \geq 24 \mathrm{~kg} / \mathrm{m}^{2}$, thereby capturing the views of those nearing (BMI $24.0-24.9 \mathrm{~kg} / \mathrm{m}^{2}$ ), as well as those already in an overweight or obese BMI classification (BMl $\geq 25$ $\mathrm{kg} / \mathrm{m}^{2}$ ). Men were eligible to participate if they were not currently attempting weight loss, were non-smokers and had no known pre-existing health conditions. By excluding men with known health conditions, the research could focus on social, and not health-related, barriers and facilitators surrounding weight behaviours. On first 
contact with the lead author, men were screened for eligibility. Following this, if still interested in participating, men scheduled to meet the first author at a public location of their choice, and of mutual convenience, (eg. pub, café) to undertake a semistructured interview and to complete a short socio-economic status questionnaire. Nineteen men agreed to be interviewed and gave informed consent. Participants could withdraw from the interview with no consequences, and from the study up to the point of data analysis. All interviews were conducted by the lead author, were digitally audio recorded, and transcribed verbatim. Transcripts were anonymised to remove identifying details such as people's names and locations discussed. Interviews lasted on average 46 minutes. A reflexive diary was used to record interactions and thoughts following the interview, these were revisited during the analysis processes ${ }^{18}$. A dictaphone with microphone was used to ensure participants could discuss topics while speaking at usual or quiet volume. Participants were provided with a $£ 15$ Amazon voucher at the end of their interview as thanks for their time.

The interview guide was developed based on literature and knowledge gaps identified in a review undertaken by the lead author. The guide was structured around the following topics: overweight and obesity, diet, physical activity, exercise, Type 2 diabetes, and weight loss groups. Verbal prompts (could you tell me more about that?) and non-verbal prompts (nodding, smiling, eye-contact) were used to encourage participants to elaborate fully on topics of relevance to the research question $^{19}$. Amendments were made to the interview guide after the first three interviews to further explore emerging themes and ideas from participants regarding social influences on their health behaviours and intentions: this resulted in the inclusion of questions that specifically asked men about perceived gender 
differences in their experiences compared to women regarding dieting, exercising and weight loss, questions about their sources of information about diet exercise and weight loss, and their thoughts on what support they might want if they were to consider losing weight.

Six participants were known to the researcher however through the use of a structured interview guide, systematic coding of data and use of multiple researchers, it is not thought that this biased the data collection or analysis process. Steps were implemented, which included carrying a personal alarm, torch, mobile phone and using public transport, to ensure researcher safety as a lone worker conducting interviews.

\section{Data Analysis}

Data analysis was primarily conducted by the lead author $[\mathrm{KH}]$ who had undertaken training in qualitative design and analysis, and had prior experience of conducting a small qualitative study. Data analysis was closely supervised and guided by two experienced qualitative researchers who also participated in initial coding of several transcripts [JA, LH]. All interviews were transcribed verbatim. Transcripts were analysed thematically using NVivo 11 software (NVivo, QSR International, 2015). Within NVivo, nodes were developed, to represent themes and sub-themes of the data. A sufficient number of participants were recruited such that coding reached saturation, and no new codes were developed during coding of the final transcript; the majority of the codes and themes had been developed in the analysis of the earlier transcripts ${ }^{20}$. All members of the research team discussed themes and subthemes alongside extracts of transcripts until any disagreements regarding analysis 
were resolved. All members of the research team are listed as authors, and all contributed to the development of the final version of results. Findings were presented and discussed in relation to the Theory of Planned Behaviour ${ }^{17}$.

\section{Ethics}

Ethical approval was granted by the University Research Ethics Committee at Oxford Brookes University (EAN: 150910).

\section{RESULTS}

Participants $(n 19)$ ranged in age from 19 to 60 years (M=44.0 SD 12.6 years) and BMI from 24.0 to $31.5 \mathrm{~kg} / \mathrm{m}^{2}\left(\mathrm{M}=27.9 \mathrm{~kg} / \mathrm{m}^{2} \mathrm{SD} 2.6 \mathrm{~kg} / \mathrm{m}^{2}\right)$. Over half of the study participants identified their marital status as being married or were living as married $(n=10) ;$ had a University degree $(n=11)$ and were working full time $(n=13)$. Four themes were inductively derived; 'how experiences shape beliefs', 'being a proper bloke', 'adapting to family life', and 'support from outside the home'. To aid understanding of how these themes influence men's behaviours they are discussed in relation to the TPB, which argues that behaviour is a result of behavioural intention, which is in turn influenced by attitudes, subjective norms and perceived behavioural control) $)^{17}$. The derived themes and sub-themes are presented in Table 1 [included at end of manuscript] in conjunction with exemplar participant quotes and participant characteristics. 


\section{Theme 1: How Experiences Shape Beliefs}

This theme suggests that past experience shaped attitudes and future behavioural intentions in relation to diet, physical activity and weight loss. Sub-themes included "integrating sport with a social life", "feeling judged by other people" and "experiences of weight loss groups".

"Integrating sport with a social life" illustrates how joining a physical activity group provided an opportunity to make friends and to be social. Two men discussed coaching sports teams, and several other participants referred to the friendships or feelings of inclusion they gained from being active with others. Being active alone was preferred by a small proportion of study participants. Making friends in a sporting context seemed socially acceptable for men and normative behaviour; almost all accounts of making friends occurred in this context. The sub-theme "Feeling judged by other people" explored how a few participants actively avoided health behaviours such as monitoring step count. Attitudes, which here appeared to be informed more by subjective norms than personal experience, included that these behaviours were seen as embarrassing and as inviting negative comments criticism or teasing or judgement. Being active in a group, however, could subvert feelings of being observed. The final sub-theme "Experiences of weight loss groups" showed that participants had little experience with commercial weight loss groups and generally felt that a weight loss group designed specifically for men was not available. This is in line with men's attitudes that weight loss groups were for women, and social norms wherein weight loss and weight loss groups attendance is not considered masculine. Experience of attending any form of weight loss group was limited to two men. One had experience of attending an employee-devised weight loss group with approximately 8 of his colleagues; his attitude was that a group 
approach enhanced his motivation to eat well and to exercise more through competitiveness. Another had attended commercial weight loss groups which was contrary to social norms for heterosexual men however this gentleman made references to having a husband: he described making friends at his group, but he also had received criticism from a female attendee.

\section{Theme 2: Being A Proper Bloke}

This theme captured the ways in which participants conceptualised their diet and activity behavioural intentions. There was a strong focus on social norms and masculinity, particularly in the younger men's narratives. Sub-themes included "pressures to diet like a man", "body image across the lifespan", and "competitiveness". "Pressures to diet like a man" showed how participants regarded weight loss groups as a "women's thing" (Participant 18): "real men" (Participant 12) would not be interested in counting calories. The terms "diet" and "dieting" were strongly associated with women, men embodied social norms by distancing themselves from these, reporting mainly negative experiences or perceptions about dieting. Many men discussed the high caloric content of alcoholic beverages but were reluctant to compromise on alcohol consumption in the company of peers for fear of censure due to contravening socially normative behaviours. It was not considered normative male behaviour to calorie count or to limit alcohol consumption for the sake of their weight and therefore they did not intend to do so. Being a "proper bloke" and adhering to social norms meant not openly discussing diet or weight concerns with friends, although some men would talk to friends, for "advice" or "hints" on these matters, and had copied a friend's or peer's weight loss diet. A small number of men made it clear that they did not receive "support" for weight loss 
171 from friends. It seemed more acceptable to seek support for health or weight from

172 online forums which could provide anonymity. Men's attitudes surrounding dieting

173 were that this was a feminine pursuit, whereas exercise was considered manly. A

174 few of the participants commented that the social norm was for male role models to

175 promote exercise, while women's role models promoted dieting.

176 The sub-theme named "Body image across the lifespan" explored how men

177 discussed their body sizes, and how perceptions about weight changed with time.

178 Approximately half of the study participants acknowledged that they were heavier or

179 larger than ideal; many seemed discontent with their bodies and described them in unflattering and emasculating ways. Over half of all participants discussed being aware of their body size and shape in relation to how their clothes fit and felt on them; old clothes felt tight, and this was a cue to lose weight. Being concerned with body image is generally not considered masculine and contradicts social norms for male bodies. A desire to fit into old clothes was a cue to lose weight; a further example of how this sample of men did not adhere to typically masculine behaviours. Two participants had received negative comments about body size from a friend or family member about a photograph of themselves which, although hurtful, had subsequently motivated them to lose weight.

The sub-theme of "Competitiveness" encapsulated interactions primarily with friends, regarding physical activity or drinking alcohol, although for one competitiveness did occur at a weight loss group with colleagues. Competitiveness was perceived as a way to demonstrate masculinity and was a powerful cue to action. 


\section{Theme 3: Adapting To Family Life}

This theme explored the ways in which men's lives had changed once children were a part of the family. The transition from bloke to family man and father precipitated a change in attitudes, beliefs and behavioural intentions. Sub-themes included "being a parent", "change in priority", "partnership" and "the control of the "housewife"'.

The sub-themes "Being a parent", and "Change in priority" focused on the experiences of four of the five men (Participants $3,5,16$ and 19) who had young children. The men's accounts conveyed a sense of responsibility about the way in which children were raised. Participants believed upbringing could influence weight status and health, therefore, to be a good father meant providing a healthy home environment. Meal times were an opportunity for everyone to be together and for fathers to spend time with their children. Families appeared to experience more barriers to being active as a unit than eating together. One participant's desire to be, and to be seen to be, a good father also prompted him to change his attitudes and behaviours towards his own weight: he wanted to be a healthy role model for his children and not to be a "fat dad" (Participant 16). Parenthood also prompted reflections on the participants' own upbringings; a small proportion of participants held the belief that the eating messages they themselves had received, had had a lasting impact on their weight.

The sub-theme "Change in priority" further highlighted how fatherhood triggered a prioritising of the needs of their family and a change in health attitudes. Instead of striving to improve body image or muscle mass through exercise, men believed it was now more important to engage in family activities such as walks, playing games in the garden or park with their children, and to prioritise health over looks. As 
fathers, men faced barriers to doing structured exercise, but saw health and social benefits of active play with their children. Being physically active with their children also formed a part of their identities as good dads and was treasured as an opportunity to promote father-child bonding: men "loved" it and thought that their children also enjoyed this, which seemed important to them.

The sub-themes of "Partnership" and "The control of the "housewife"' focus on relationship influences and perceived behavioural control. Many of the participants talked about having a girlfriend, partner or wife, and there was a strong sense of togetherness in the way they spoke about their partners. For a small proportion of study participants, partnership meant taking it in turns to go to the gym because of shared childcare duties, or cooking and making food choices together.

Approximately one quarter of study participants discussed goal-setting and making lifestyle changes with their partner. They framed partners as a buddy; someone they felt comfortable discussing their personal goals with, and someone who facilitated their goals by sharing them. However, "The control of the "housewife"' captured how participants framed their female partners as being in control of the kitchen, responsible for household nutrition, and how they lacked control over aspects of their weight-related behaviours. Two participants discussed how their meals would be decided and prepared by their partner and they perceived they lacked control over what they ate. Male attitudes were that partners were viewed as primarily facilitating weight loss through nutrition rather than physical activity. Although being a "proper bloke" meant being in control, only two participants seemed to discuss being in control of their dietary choices. Indeed, several participants described ways in which their partners encouraged or facilitated unhealthy behaviours. One participant revealed how he and his girlfriend appeared to have developed joint unhealthy 
eating habits through a shared and mutually reinforcing attitude about what they felt constituted a healthy diet. One man felt perceived he lacked control to abstain from drinking when his wife opened a bottle of wine, whereas another thought that not having a partner to cook healthy meals for him was a barrier to healthy eating. Additionally, a small number of participants discussed how the food preferences of their partners were a barrier to eating some foods (such as fish and meat) together.

\section{Theme 4: Support From Outside The Home}

Most participants talked about having someone in their lives that they would turn to for advice or support when engaging in weight loss behaviours. For some, support came from within the home but others sought advice from professionals, or infrequently, from personal trainers. Sub-themes included "GP support", "perceptions about support from weight loss groups" and "personal trainer support".

The sub-theme "GP support" captures the positive attitudes that most men had of their GP or other health-care professional. A shared subjective norm respecting advice from health professionals was apparent, and GP advice was generally respected and considered reliable, and participants talked about ways in which GP support, or better GP support, would have benefited weight loss efforts. Some men voiced frustrations or feelings of being let down by their GP, or the lack of dietary guidance provided by their GP. GPs were trusted to care for participants' health and raise any issues regarding weight, diet, exercise, risk of disease that were necessary particularly in the absence of a partner. Participants interpreted an absence of these conversations as a signal that they did not need to undertake weight loss. Contrary to the general consensus, one participant was deterred by the potential for 
embarrassment from heeding his doctor's encouragement and incentives to attend a weight loss group.

The sub-theme "perceptions about support from weight loss groups" highlighted men's perceptions of key aspects of a desirable weight loss group for men. A crucial element was the possibility of one-to-one support, ensuring men had the opportunity to privately discuss their concerns and progress with the group leader. Participants were almost equally divided about whether they would prefer a single or mixed sex group. Some were happy to attend a mixed-sex weight loss group with partners, because they thought weight was an issue among men as well as women; other's preferred a "blokes-only" approach. Many participants thought that weight loss groups could be very supportive; members could share weight loss goals and also make friends.

The sub-theme "Personal trainer support" encompassed the views of a small number of participants who discussed personal trainers and health coaches. These men valued having someone to instruct them, and importantly it seemed more acceptable to seek professional support than to ask friends for support. Personal trainers were perceived to be knowledgeable, trusted sources of information, physical activity experts and in a small number of instances, nutrition experts. In one instance, a personal trainer was specifically enlisted to help a young participant (Participant 15, aged 19) become fitter in order to reduce his risk of future ill health.

This small qualitative study explored the social influences on men's nutrition, physical activity and weight loss behaviours among a sample of 19 men in a single 
county in South West England. Findings are thus limited to this demographic and may not be transferable to other settings. Within the small sample, men's accounts seemed to vary depending on where they were in their life trajectory; those without children or partners focused more on fitness and body image, those with younger children focused on health and active play. Older participants without a partner relied on the GP for health advice, whereas those with a partner sought advice from them. The themes generated from the data analysis will now be further discussed in relation to the wider literature and the TPB ${ }^{17}$.

The findings of this study, in agreement with other literature, indicated that perceived gender norms and a strong belief about the femininity of weight loss groups appears to be negatively associated with men's behavioural intentions around dieting and participating in weight loss groups ${ }^{21}$. Social norms encourage male bodies to be large and muscular, discouraging weight loss efforts ${ }^{22,23}$. Among this small sample of men, low perceived behavioural control over aspects of their diet and health, low autonomy over their food choices, and a belief that women knew more about nutrition than they did reduced their behavioural intentions to modify their diet, as also seen in other research ${ }^{13,14,24,25}$. It has been previously found that women are the household members who undertake the majority of food work in the home ${ }^{14,26 \text {, }}$ 27. Men stereotypically delegate responsibility for their health care to their female partners and men are often passive receivers of care by way of adhering to gender norms ${ }^{8,28}$. Concurrent with UK, US and Australian-based literature, this study found that men predominantly relied on partners for diet support ${ }^{29,30}$. However, the current study also highlights how participants' female partners could be seen as a barrier, or could introduce barriers to men's weight loss efforts. Some men therefore may be more likely to react negatively to a dietary regime which they may perceived as 
compromising aspects of their masculinity, or poor dietary knowledge, habits or preferences of a partner could impede men's healthy eating behaviours.

In line with traditional gender norms, some men within this study held the attitude that it was not appropriate to discuss dieting intentions or behaviours with friends. This finding resonates with Australia research with obese (BMI $\geq 30 \mathrm{~kg} / \mathrm{m} 2)$ men $(n=36)^{23}$. Our findings that men perceived it as favourable to exercise with a group of men particularly with whom they share commonalities, were also supported by other research ${ }^{31}$. Generally speaking, other research has found that younger men are motivated to lose weight to improve body image, and older men do so for health ${ }^{32}$. The assertion by the youngest participant in the current study, that he was motivated to lose weight to improve his health, challenges previous understandings of young male's weight loss motives. If found to hold true among a larger sample of young men, this could indicate a potential for health-based weight loss interventions to be of interest to both younger and older men. While the wider literature suggests men avoid seeing their GP unless pressured by a partner ${ }^{28,33}$, and have fewer health consultations than women ${ }^{34}$, the current study highlights the potential positive role for GPs to influence men's weight loss efforts.

The potential to harness fathers' motivation to be a healthy role model for their children is an important finding of this study. A similar finding regarding men's desire to be a healthy role model for their children was also found among men in The Netherlands ${ }^{28}$. Father-child bonding has been utilised as a lever for health among men in the Australian "Healthy Dads, Healthy Kids" study ${ }^{35}$ : however, the research found greater improvements in the fathers' physical activity behaviours than their dietary behaviours. The current study highlighted men's perceived interest in their 
children's nutrition, however it was usually female partners who provided meals for the whole family.

Using the TPB to understand men's discussions surrounding weight loss behaviours, several key findings emerged; men's attitudes about the dietary knowledge women hold, the perceived control that women have over food in the home, and men's acceptance that nutrition and dieting are feminine activities, resulted in limited talk of "dieting" experience. Men's positive attitudes surrounding the role that physical activity played in health and weight loss influenced their actions; fathers engaged in physical activity with their children to be a good dad, and to be healthier and to improve their child's health. Men prioritised time to be active with their children than to exercise alone. This study also found that men who were fathers often experienced a lack of control over family food intake and were unable to use this as their way to be a healthy role model for their children, so instead, they educated their children about healthy eating and physical activity. Overall, the TPB provided a useful tool to organise and interpret the study findings. However, the role of past experience was not accounted for in the model but emerges as a contributing factor to attitudes and behavioural intentions in the current study.

\section{Limitations}

Since the conclusions drawn are based on a small convenience sample of men the findings from this research may not be transferable to other settings. The study results could have been improved if BMI had been objectively measured rather than self-reported, however due to the nature of the interview locations, this was not appropriate. It was considered that the use of a public space to conduct interviews 
could have had implications regarding data quality, however, a more natural setting was chosen over an institutional setting to ensure participants felt comfortable and not intimidated by the "interview" process. Furthermore, no direct comparison group of women were interviewed as a part of this research study and therefore the conclusions drawn and comparisons made between men and women have limitations. Anonymity issues relating to small sample size, public interview location and restriction of recruitment to one county were addressed and mitigated against. Further limitations include the use of one coder for the majority of the transcripts with limited reliability information, who coded all interviews. While steps were undertaken to minimise bias and multiple researchers were involved in transcript coding, it is likely that bias was not eliminated. The acquaintance of the lead author who conducted interviews with six of the participants is a limitation regardless of the steps that were undertaken to minimise this bias.

\section{Implications For Research And Practice}

The results from this small qualitative study suggest that weight loss behaviours are influenced by concepts of masculinity which develop and change over the life span. Since men do not enact masculinity equally ${ }^{36}$, future research may seek to explore weight loss behaviours beyond gender alone and consider further the social, cultural and physical context across the lifespan. Greater insights into the nature of social influences would have been uncovered if interviews with the men's partners, individually and as a couple had been undertaken. This study provides rich accounts and context surrounding the social influences men discussion in relation to their dietary, exercise and weight-related intentions and behaviours. It is the first study to 
explore this topic among men who may be at risk of overweight (BMI 24.0-24.9 $\mathrm{kg} / \mathrm{m}^{2}$ ) and to report detailed participant characteristics.

\section{Funding}

This research was funded by [University studentship]

\section{Declaration Of Conflicting Interests}

The Authors declare that there is no conflict of interest

\section{References}

1. Shaw KA, Gennat HC, O'Rourke P, Del Mar C. Exercise for overweight or obesity. The Cochrane Library. 2006.

2. Moody A, Neave A. Health Survey for England 2015 Adult overweight and obesity. 2016.

3. Di Angelantonio E, Bhupathiraju SN, Wormser D, et al. Body-mass index and all-cause mortality: individual-participant-data meta-analysis of 239 prospective studies in four continents. The Lancet. 2016;388:776-786.

4. Pagoto SL, Schneider KL, Oleski JL, Luciani JM, Bodenlos JS, Whited MC. Male inclusion in randomized controlled trials of lifestyle weight loss interventions. Obesity. 2012;20:1234-1239. 
410

411

412

5. Slimming World Company Data. Percentage of men attending Slimming World in 20162016.

6. Monaghan LM, Malson H. 'It's worse for women and girls': negotiating embodied masculinities through weight-related talk. Critical Public Health. 2013;23:304-319.

7. Newcombe MA, McCarthy MB, Cronin JM, McCarthy SN. "Eat like a man". A social constructionist analysis of the role of food in men's lives. Appetite. 2012;59:391-398.

8. Courtenay WH. Constructions of masculinity and their influence on men's well-being: a theory of gender and health. Social science \& medicine. 2000;50:1385-1401.

9. Sobal J, Rauschenbach B, Frongillo EA. Marital status changes and body weight changes: A US longitudinal analysis. Social Science \& Medicine. 2003;56:1543-1555.

10. Golan R, Schwarzfuchs D, Stampfer MJ, Shai I. Halo effect of a weight-loss trial on spouses: the DIRECT-Spouse study. Public Health Nutr. 2010;13:544549.

11. Mallyon A, Holmes M, Coveney J, Zadoroznyj M. I'm not dieting, 'I'm doing it for science': Masculinities and the experience of dieting. Health Sociology Review. 2010;19:330-342.

12. Martinez JBSN, Powell JMPH, Agne AMPH, Scarinci IPMPH, Cherrington AMDMPH. A Focus Group Study of Mexican Immigrant Men's Perceptions of Weight and Lifestyle. Public Health Nursing. 2012;29:490.

13. Maclean A, Hunt K, Gray C, Smillie S, Wyke S. How Do Men's Female Relatives Feature in Their Accounts of Changing Eating Practices During a 
Weight-Management Programme Delivered Through Professional Football Clubs? International Journal of Men's Health. 2014;13:121-138.

14. Allen JO, Griffith DM, Gaines HC. "She looks out for the meals, period": African American men's perceptions of how their wives influence their eating behavior and dietary health. Health Psychology. 2013;32:447.

15. Kumanyika SK, Wadden TA, Shults J, et al. Trial of family and friend support for weight loss in African American adults. Arch Intern Med. 2009;169:17951804.

16. Griffith DM, King A, Allen JO. Male peer influence on African American men's motivation for physical activity: Men's and women's perspectives. American Journal of Men's Health. 2013;7:169-178.

17. Ajzen I. The Theory of Planned Behavior. Organizational Behavior and Human Decision Processes. 1991;50:179-211.

18. Nadin S, Cassell C. The use of a research diary as a tool for reflexive practice: Some reflections from management research. Qualitative Research in Accounting \& Management. 2006;3:208-217.

19. Bowling A. Research methods in health: investigating health and health services: McGraw-Hill Education (UK); 2014.

20. Guest G, Bunce A, Johnson L. How many interviews are enough? An experiment with data saturation and variability. Field methods. 2006;18:59-82.

21. Hunt K, Gray CM, Maclean A, Smillie S, Bunn C, Wyke S. Do weight management programmes delivered at professional football clubs attract and engage high risk men? A mixed-methods study. BMC Public Health. $2014 ; 14: 1-11$. 
22. Sabinsky M, Toft U, Raben A, Holm L. Overweight men's motivations and perceived barriers towards weight loss. European Journal of Clinical Nutrition. 2007;61:526-531.

23. Lewis S, Thomas SL, Hyde J, Castle DJ, Komesaroff PA. A qualitative investigation of obese men's experiences with their weight. American Journal of Health Behavior. 2011;35:458-469.

24. Ashton LM, Hutchesson MJ, Rollo ME, Morgan PJ, Thompson DI, Collins CE. Young adult males' motivators and perceived barriers towards eating healthily and being active: A qualitative study. The International Journal of Behavioral Nutrition and Physical Activity. 2015;12.

25. Jackson SE, Steptoe A, Wardle J. The influence of partner's behavior on health behavior change: the English Longitudinal Study of Ageing. JAMA Internal Medicine. 2015;175:385-392.

26. Roos G, Prättälä R, Koski K. Men, masculinity and food: interviews with Finnish carpenters and engineers. Appetite. 2001;37:47-56.

27. Lupton D. 'Where's me dinner?': food preparation arrangements in rural Australian families. Journal of Sociology. 2000;36:172-186.

28. Verdonk $\mathrm{P}$, Seesing $\mathrm{H}$, de Rijk A. Doing masculinity, not doing health? A qualitative study among Dutch male employees about health beliefs and workplace physical activity. BMC Public Health. 2010;10:712.

29. De Souza P, Ciclitira KE. Men and dieting: a qualitative analysis. Journal of Health Psychology. 2005;10:793-804.

30. Snipes SA, Hayes Constant TK, Trumble BC, et al. Masculine perspectives about work and family concurrently promote and inhibit men's healthy behaviors. International Journal of Men's Health. 2015;14:1-20. 
31. Bunn C, Wyke S, Gray CM, Maclean A, Hunt K. 'Coz football is what we all have': masculinities, practice, performance and effervescence in a gendersensitised weight-loss and healthy living programme for men. Sociology of Health \& IIIness. 2016;38:812-828.

32. Sabinsky MS, Toft U, Raben A, Holm L. Overweight men's motivations and perceived barriers towards weight loss. European Journal Of Clinical Nutrition. 2007;61:526-531.

33. Sharpe S, Arnold S. Men, lifestyle and health: a study of health beliefs and practices. Unpublished research report. 1998.

34. Wang $\mathrm{Y}$, Hunt $\mathrm{K}$, Nazareth I, Freemantle N, Petersen I. Do men consult less than women? An analysis of routinely collected UK general practice data. BMJ open. 2013;3:e003320.

35. Morgan PJ, Lubans DR, Plotnikoff RC, et al. The'Healthy Dads, Healthy Kids' community effectiveness trial: study protocol of a community-based healthy lifestyle program for fathers and their children. BMC Public Health. 2011;11:876.

36. Sloan C, Gough B, Conner M. Healthy masculinities? How ostensibly healthy men talk about lifestyle, health and gender. Psychology and Health. 2010;25:783-803. 
Table. The Influence of Social Relationships on Men's Weight

\section{Theme}

How experiences

shape beliefs

Being a proper bloke

$$
\begin{aligned}
& \text { Pressures to diet like } \\
& \text { a man }
\end{aligned}
$$

Body image across the life span

Adapting to family life

Being a parent

Change in priority

Partnership

The control of the

"housewife"

Support from

outside the home
Competitiveness

\section{Quote}

I do squash, several of my good mates, my long-term mates I met through squash.

They're worried that they might get judged and people will look at them, and to be fair, if I go [to the gym] ... there will be people who can lift weights way higher than me and they're definitely looking at me.

I heard the consultant say, "Our Slimmer of the Week is [participant's name]." I heard the person behind me say, "Well, yes, he always gets it because men lose weight faster. " And I was, "Wow, thanks for ripping that one out of my hands.

I wouldn't go and see my mates and say, "I want to lose a bit of weight, what do you think I should do?" We would never talk about something like that. The friends I've got are my best friends, they've been my friends for 30 , however many years... we don't talk about things like that.

I had a picture with my girlfriend... One of my friends went, "Ah, what have you got up there, a spare tyre!" And actually you could see my fat podg. ing around the side of my T-shirt, and I was like, ok I need to do something.

Squash - love it. I go off there and I am absolutely bloody soaked. [daughter's boyfriend] is, what, twenty-odd years younger than me, and he comes off equally drenched - I ensure of that [laughter]. Too right, "If I'm coming off soaking wet so are you, mate!" [laughter] ... I am quite competitive when / get going...

I want to lose weight. It's just what I want to do. You don't want to be a fat dad, do you?

Body image isn't that important to me anymore... It goes back to the point of where I am in my life... What I need from my training is to be more physically fit and healthy rather than how big and how ugly and how, how I'm going to look.

I'd even say a dieting buddy, a healthy eating buddy then... So / suppose I've got that in my wife that we, kind of, set similar goals.

When you come home from work at night, if tea's cooked, you eat it. It. doesn't mean I had a choice of saying what I wanted to eat.

Every time I go to the doctor, he's never mentioned me going on a diet, you know.

.. have a little catch-up quietly one-to-one. I hate the thought of that middle of the stage scales and everybody rolls up and, "Ooh, yeah. "It's done

Perceptions about support from

weight loss groups

Personal trainer

support quietly, it's done individually, it's done respectfully.

So l've got a coach, like a supervisor, who will guide me through my products, and it's because, well I haven't got time and I can't really be bothered to cook.
Participant Information

Participant 17 , aged $47 \mathrm{y}$,

BMI $26.0 \mathrm{~kg} / \mathrm{m}^{2}$, divorced Participant 3 , aged $31 \mathrm{y}$,

BMI $25.4 \mathrm{~kg} / \mathrm{m}^{2}$, married

Participant 13 , aged $40 \mathrm{y}$, BMI $31.5 \mathrm{~kg} / \mathrm{m}^{2}$, married

Participant 5, aged $37 \mathrm{y}$, BMI $26.9 \mathrm{~kg} / \mathrm{m}^{2}$, married

Participant 3 , aged $31 \mathrm{y}$, BMl $25.4 \mathrm{~kg} / \mathrm{m}^{2}$, married

Participant 16 , aged 45 y, BMI $25.0 \mathrm{~kg} / \mathrm{m}^{2}$, married

Participant 16 , aged $45 y$, BMI $25.0 \mathrm{~kg} / \mathrm{m}^{2}$, married Participant 19 , aged $46 \mathrm{y}$. BMI $29.2 \mathrm{~kg} / \mathrm{m}^{2}$, married

Participant 5, aged $37 \mathrm{y}$, BMI $26.9 \mathrm{~kg} / \mathrm{m}^{2}$, married Participant 16 , aged $45 \mathrm{y}$, BMI $25.0 \mathrm{~kg} / \mathrm{m}^{2}$, married Participant 14 , aged $60 \mathrm{y}$, BMI $26.1 \mathrm{~kg} / \mathrm{m}^{2}$, divorced Participant 6, aged $56 \mathrm{y}$, BMI $24.0 \mathrm{~kg} / \mathrm{m}^{2}$, widowe

Participant 15 , aged $19 \mathrm{y}$, BMI $30.1 \mathrm{~kg} / \mathrm{m}^{2}$, single 